\title{
Computational Tool for Post-Earthquale Evaluation of Damage in Buildings
}

\author{
Martha L. Carreño, ${ }^{\text {a) }}$ Omar D. Cardona, ${ }^{\text {b) }}$ M.EerI, and Alex H. Barbat, ${ }^{\text {c) }}$ \\ M.EERI
}

A method and a computational tool oriented to assist the damage and safety evaluation of buildings after strong earthquakes is described in this article. The input of the model is the subjective and incomplete information on the building state, obtained by inspectors which are possibly not expert professionals of the field of building safety. The damage levels of the structural components are usually described by linguistic qualifications which can be adequately processed by computational intelligence techniques based on neuro-fuzzy systems what facilitate the complex and urgent tasks of engineering decision-making on the building occupancy after a seismic disaster. The hybrid neuro-fuzzy system used is based on a special three-layer feedforward artificial neural network and fuzzy rule bases and is an effective tool during the emergency response phase providing decisions about safety, habitability, and reparability of the buildings. Examples of application of the computer program are given for two different building classes.

[DOI: 10.1193/1.3282885]

\section{INTRODUCTION}

Actual design criteria, which are based on structural ductility and redundancy, assure the security of the buildings against collapse but not damage. Accordingly, seismic codes accept heavy damage without collapse of the buildings in the case of severe earthquakes. But there are seismic areas where many existing buildings are designed according to obsolete seismic design codes or are built without the use of any earthquake resistant provisions. As such, many buildings are damaged at different degrees during strong earthquakes, and their safety is doubtful. In obtaining an urgent diagnosis on the state of a building after an earthquake, which has to provide reliable information on its habitability and reparability, it is necessary to take into account not only the different damage levels of the elements, but also the overall structural stability. Therefore, it is necessary to carry out an accurate process of damage evaluation that requires the participation of professional experts in the field of structural and soil mechanics, damage evaluation, and building rehabilitation.

\footnotetext{
a) International Center for Numerical Methods in Engineering, c/o Jordi Girona 1-3 Módulo C1, 08034 Barcelona, Spain. Phone: (+34) 934016496, Fax: (+34) 934011048. liliana@cimne.upc.edu

b) Universidad Nacional de Colombia, Carrera 27 No 64-60, Manizales, Colombia. Phone: (+571) 5300828, Fax: (+571) 5300827. odcardonaa@unal.edu.co

c) Technical University of Catalonia, C/Jordi Girona 1-3 Módulo C1, 08034 Barcelona, Spain. Phone: (+34) 934016496, Fax: (+34) 934011048. alex.barbat@upc.edu
} 
When the seismic damage has to be evaluated in a whole urban area struck by a severe earthquake, the number of required professionals with the necessary experience to perform the damage assessment is always insufficient. But the nonexperts who have to be involved tend to overestimate or to underestimate damage because of their inexperience. Moreover, the information obtained by all evaluation methods is highly subjective, because the damage levels are defined with linguistic qualifications such as light, minor, moderate, average, severe, etc., which have a remarkable variation in their meaning according to the person who uses them.

Computational intelligence techniques and the decision-making needed for soft computing can be used to overcome these difficulties of damage evaluation after earthquakes (ex post; Carreño et al. 2006). The same approach has been used in previous works to make evaluations of the expected urban seismic risk in an urban area (ex ante; Cardona 2001, Carreño et al. 2007a) and to measure the disaster risk management performance and effectiveness at national, subnational, and local levels (Carreño et al. 2007b). Applying computational intelligence techniques and the decision-making needed to determine the habitability and reparability of the buildings affected by an earthquake, it is possible to avoid or reduce the usual mistakes made by nonexpert building inspectors
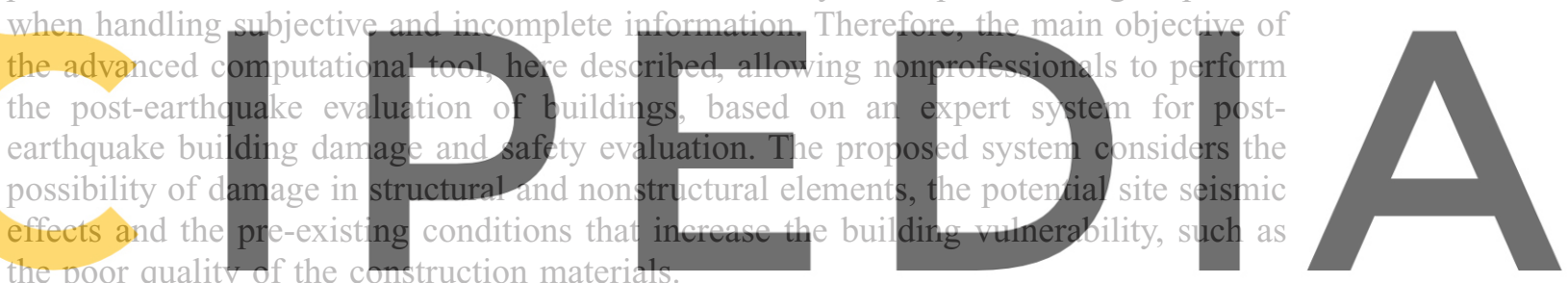

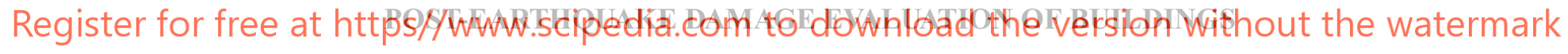

Decision-making about the safety, habitability, and reparability of buildings based on the complex patterns of the observed damage is really difficult task, particularly for nonexpert professionals. For example, during strong earthquakes, in the columns of reinforced concrete buildings appear diagonal cracks due to shear or torsion while vertical cracks, concrete cover spalling, concrete crush, and buckling of the longitudinal reinforcing bars occur due to bending and compression. The most typical damages in beams are the diagonal cracks and the stirrup failure due to shear or torsion and vertical cracks, longitudinal reinforcement failure, and concrete crush due to the bending to alternating loads. The beam-column joints usually show diagonal cracks as a result of shear stresses, and their failure is common due to the lack of anchorage of the longitudinal reinforcement of the beams into the joint or due to excessive bending. The slabs can show punching shear cracks around the columns and longitudinal cracks due to bending. The damage in nonstructural elements represents a high proportion of the total damage caused by an earthquake. Usually, it occurs due to inappropriate connections between infill panels, installations or other nonstructural components and the structure. It can be also produced by the excessive flexibility of the structures, which results in excessive inter storydrift. In masonry partitions and façades, the diagonal cracks are common. 
When evaluating the structural and nonstructural state of buildings, inspectors who lack training and qualifications have the tendency of aggravating or underestimating the observed damage level. The information obtained during the damage evaluation process becomes thus highly subjective. With the objective of making correct decisions on the state of the buildings, the nonexpert professionals have to use appropriate guidelines and be supervised by expert inspectors. Consequently, efforts in developing damage evaluation methodologies and guidelines have been made in different countries with high seismic activity, aiming to help in defining accurate and effective measures of repairing the damaged buildings and to avoid such decisions as unnecessary demolitions. These guidelines allow one to decide rapidly if a building may continue being used or not, and to identify safe buildings which can be used as temporary shelters for the evacuated persons. Even so, one of the shortcomings of damage evaluation processes is their subjectivity, because damage levels are defined using linguistic qualifications like light, moderate, or severe, which may have different meanings according to the judgment of each person. Poor-quality data and the lack of systematization contribute to the confusion and to the delay in relevant disaster management decisions. Therefore, it is necessary to have in advance a contingency plan in which the damage evaluation process is one of the main tasks.
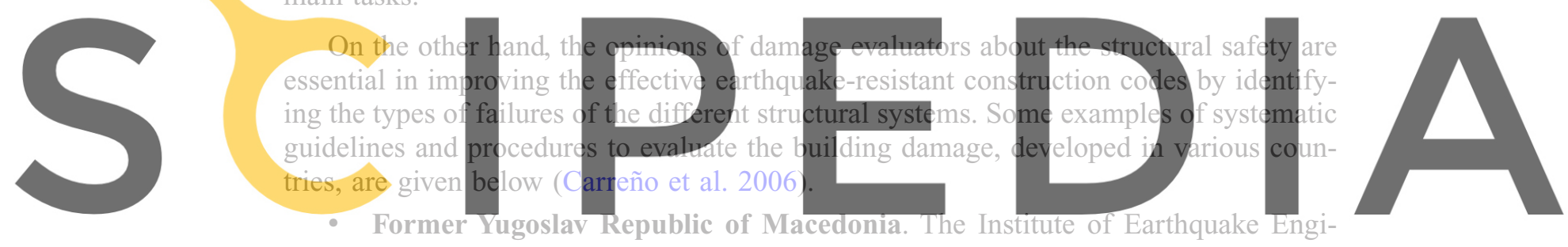

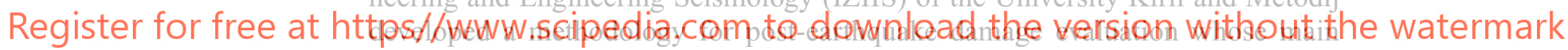

objectives are data acquisition regarding the available housing, destroyed buildings and unsafe buildings (IZIIS 1984). Data acquisition for civil protection, rescue planning and post-earthquake organization as well as the improvement of the design specifications of the earthquake resistant codes are also important objectives.

- California. The Applied Technology Council proposed the Procedures for PostEarthquake Safety Evaluation of Buildings as a standard for the safety investigation of buildings based on visual observation of damage with three levels of building evaluation. The first level is the Rapid Evaluation, in which it is decided whether buildings are safe enough to occupy shortly after the earthquake. In the second level, a Detailed Evaluation is performed, in which the questionable structures are visually evaluated by a structural engineer (ATC-20 1989, ATC-20i 2003, ATC-20-1 2005). The third level is the Engineering Evaluation, which is required when the structure cannot be appraised by visual techniques alone. Procedures for these detailed engineering damage evaluations and repair techniques were developed in FEMA 306 and FEMA 351 for concrete and masonry buildings and for welded steel moment-frame buildings respectively (FEMA 1998 and 2000). Consequently, these documents supplement the provisions of ATC-20. 
- Japan. After the Miyagiken-Oki earthquake of 1978, the Guides for Damage Evaluation After an Earthquake and Restore Techniques were published in Japan and reviewed in 1989. Accordingly, the buildings which have to be evaluated are selected by a general inspection after the earthquake. The evaluation is performed in two steps: an immediate visual evaluation of the damage level and of the habitability, and then the evaluation of the degree of structural damage.

- Mexico. The Institute of Engineering of the National University (UNAM) developed the Guideline for Post-Earthquake Evaluation of the Structural Safety of Buildings (Rodríguez and Castrillón, 1995). This methodology was reviewed and published by the Mexican Society for Earthquake Engineering (SMIS) and the government of Mexico City in 1998 (SMIS 1998) and has three steps: a rapid evaluation, a detailed evaluation, and a specialized engineering evaluation.

- Italy. After the earthquake of Friuli in 1976, a procedure for estimating economic losses was developed. Guidelines and forms were published in 2000. More recently, a proposal was published by Goretti (2001) based on a research program started in 1995. In addition, a multimedia tool: MEDEA (Manualle di Esercitazioni sul Danno Ed Agibilitá), with a catalog of the more relevant dam-

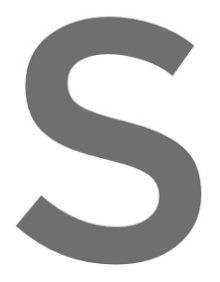
ages on structural and nonstructur
developed by Zuccaro and Papa (2
Colombia. After the Coffee-Grow
ducted on the seismic vulnerability
methodology for the evaluation of t
case of earthquakes, based on a
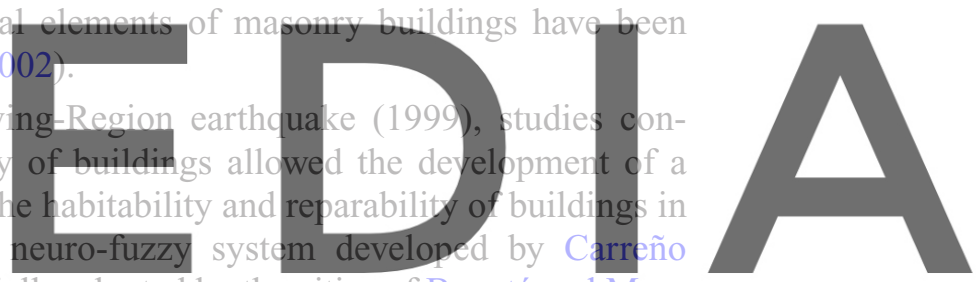

(2001). The methodology was officially adopted by the cities of Bogotá and Manizales (AIS 2002, 2003a). It includes an evaluation form and a field manual for

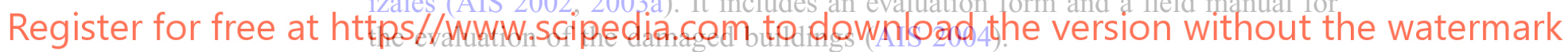

\section{SEISMIC DAMAGE EVALUATION MODEL}

The existing methodologies and guidelines for the seismic damage evaluation of buildings cannot avoid certain decision mistakes, like the demolition of noncritical buildings or unnecessary building evacuation, especially due to the lack of experience and qualifications of volunteer inspectors after a strong earthquake. It is also possible that nonexpert inspectors ignore building damage that can put at risk structural stability and safety. To overcome this problem, an expert system and a computational tool have been developed for the emergency response phase after strong earthquakes (Carreño et al. 2006, Carreño 2006).

This expert system for seismic damage evaluation of buildings as a support to habitability evaluation is based on artificial neural networks and fuzzy sets. The authors have been working in this model since 2000, and although this tool has not been tested yet in a real earthquake emergency, recently it has been adopted officially by the administrations of the cities of Bogotá and Manizales, in Colombia, to face future earthquakes and to complete its calibration. The model uses a fuzzy logic approach, required to process the subjective and possibly incomplete available information that is usually based 

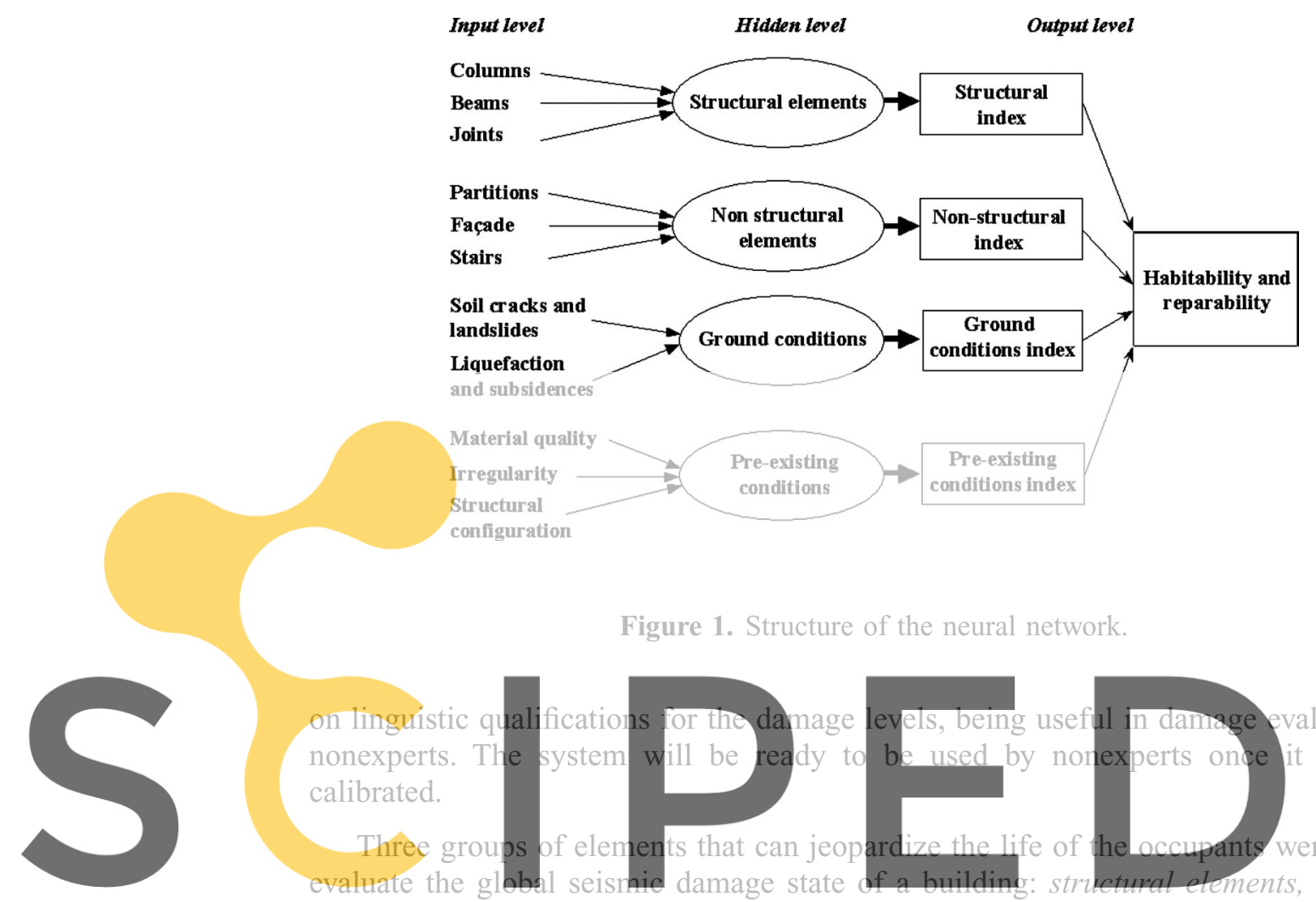

Figure 1. Structure of the neural network.

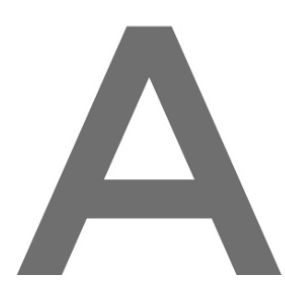

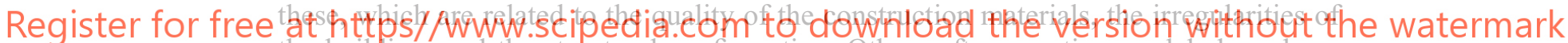

the building, and the structural configuration. Other soft computing models have been

developed for the latter evaluation, from an ex ante perspective by Sanchez-Silva and

Garcia (2001) and Demartinos and Dritsos (2006).

The proposed ex post model and computational tool use an artificial neural network (ANN). A detailed description of ANN as used is given in the Appendix A. It has three layers, and Figure 1 shows its general structure. The neurons of the input layer are grouped in four sets, corresponding to the structural elements (SE), nonstructural elements (NE), ground conditions (GC), and pre-existent conditions (PC). Each one contributes with information to the neurons in the intermediate layer. They only affect the intermediate neuron in the group to which they belong. The number of input neurons of the model is not constant; it depends on the structural system and on the importance of the groups of variables that influence on the evaluation. For example, if structural damage is very high, it is not necessary to evaluate the ground conditions or the pre-existent conditions.

The number of neurons of the input layer used to analyze the state of the structural elements changes according to the class of building. Table 1 shows the structural variables considered according to the structural system. 
Table 1. Structural elements according to structural system (AIS 2003b)

\begin{tabular}{cc}
\hline \hline Structural system & Structural elements \\
\hline RC & Columns/walls, beams, joints and floors \\
Steel & Columns, beams, connections and floors \\
Unreinforced/Reinforced/Confined & Bearing walls and floors \\
Bahareque & Bearing walls and floors \\
\hline \hline
\end{tabular}

A qualification is assigned to structural and nonstructural elements, depending on the observed damage using five possible damage levels that are represented by means of fuzzy sets: none, light, moderate, heavy, and severe. Figure 2 illustrates the membership functions for these qualifications. The membership functions of the fuzzy sets reach their maximum membership point for the values of the damage indices.

The damage in of nonstructural elements does not affect the overall stability of the buildings, but may put at risk the security of the occupants, as it is the case of the staircase of Figure 3. The nonstructural elements are classified in two groups: elements whose evaluation is compulsory and elements whose evaluation is optional (see Table 2).

The ground and pre-existent conditions variables are qualified during the evaluation process. The used linguistic qualifeat ons are: very good, medium, and very bad. Ground conditions like it can be seen struetion matelials, the
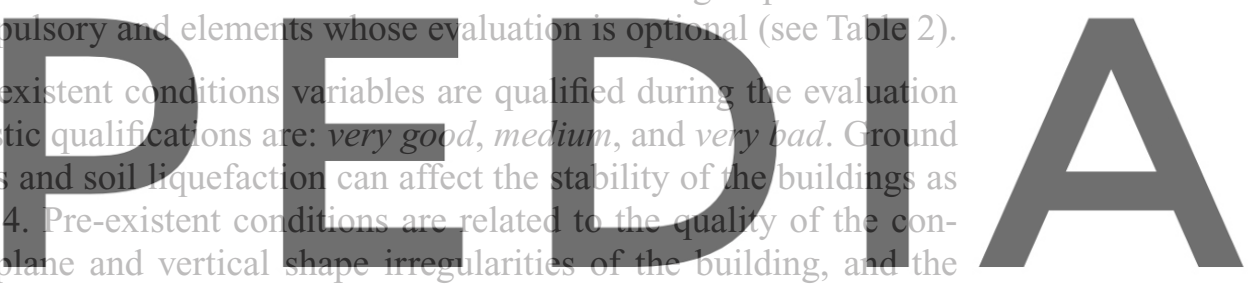

structural configuration; these conditions may increase the seismic vulnerability of a

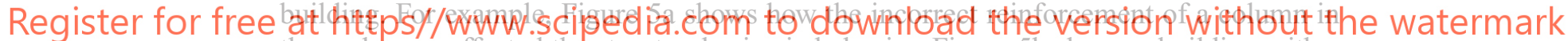

the node area affected the structural seismic behavior. Figure $5 \mathrm{~b}$ shows a building with a soft first floor and with the unconfined masonry infill. Figure $5 \mathrm{c}$ shows a case of inadequate structural configuration.

In the intermediate layer, an index is obtained by the union and defuzzification of each group of variables (structural elements, nonstructural elements, ground conditions,

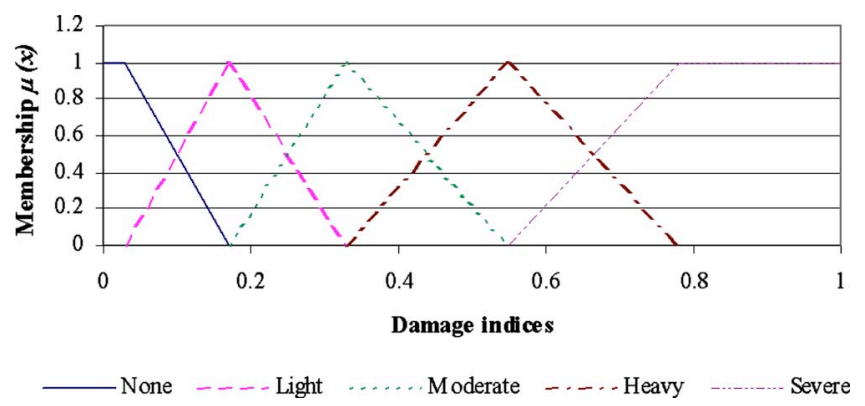

Figure 2. Membership functions for linguistic qualifications (AIS 2003b). 

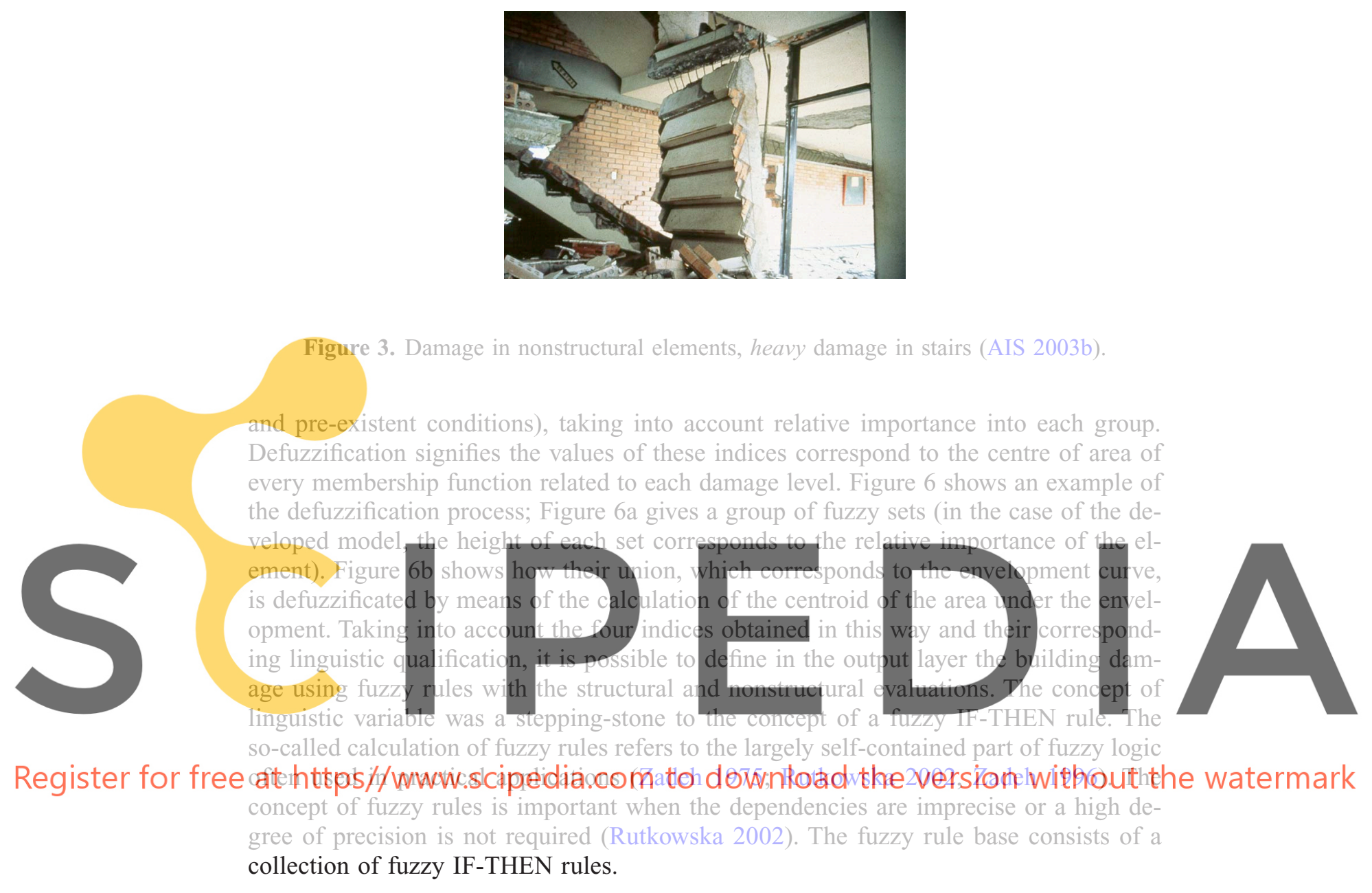

According to the proposed fuzzy rules, building habitability is decided by using the evaluation of the structural and nonstructural states but also by assessing the ground conditions. Finally, using the pre-existent conditions, the computational tool defines the required level of reparation providing also habitability and reparability recommendations after an earthquake. Remarks as: "habitable after minor adequateness" or "restricted: us-

Table 2. Nonstructural elements (AIS 2003b)

\begin{tabular}{cc}
\hline \hline & Partitions \\
Compulsory evaluation elements & Elements of façade \\
& Stairs \\
& Ceiling and lights \\
Optional evaluation elements & Installations \\
& Roofs \\
& Elevated tanks \\
\hline \hline
\end{tabular}




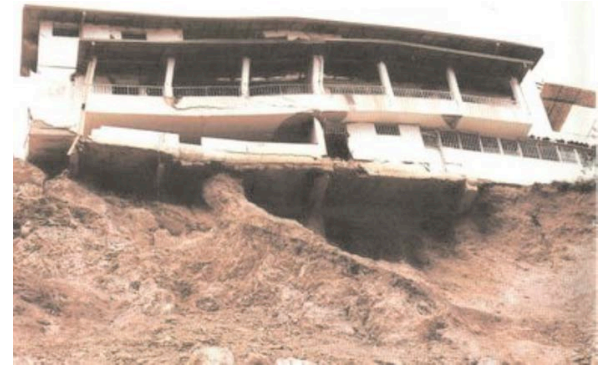

Figure 4. Ground conditions, landslides and ground failure.

able after reparation" or "unsafe: usable after structural strengthening or reinforcement" or "dangerous: possible demolition or total building rehabilitation," are decisions made by the expert system.

Training in the expert system proposed in this manuscript was carried out using the

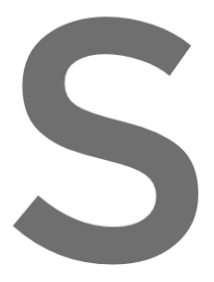
latabase that contains d Region earthqua

Earthquake En and the Kohon reinforced-conce been used in the damage informati tains damage evaluations
in dolombia (1999)
rate of learning ( see t
ce frames and 100 build
on about the structural an

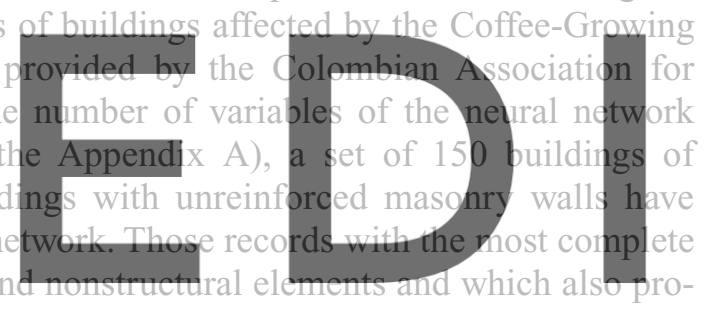
A

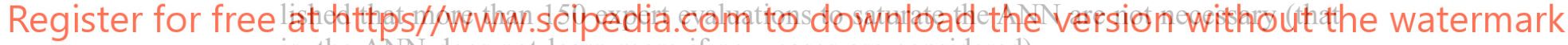
is, the ANN does not learn more if new cases are considered).

However, more information is necessary to complete the network training for all structural classes, especially for wood- and steel-framed structures, because these building classes are not common in that area. There are also only a few reinforced-concrete frames with shear, and therefore, the number of building evaluations to calibrate this structural system has been insufficient. On the whole, it is desirable to have more cases for all structural classes.

The indices of each damage level as well as the relative weights for each group of elements have been calibrated. Appendix A gives detailed information about the calibration or learning process of the neural network; specifically about the calibration of the weights.

In the case of the damage indices, calibration starts from the initial indices - or central value - of each damage states. The damage levels proposed in ATC-13 (1985), the fragility curves proposed by Singhal and Kiremidjian (1996) and used by HAZUS-99 (FEMA 1999), the indices of Park et al. (1984), of Sanchez-Silva and García (2001), as well as damage indices based on energetic criteria and on nonlinear structural analysis (Barbat et al. 1997, Oller and Barbat 2006), have been considered for the neural network 


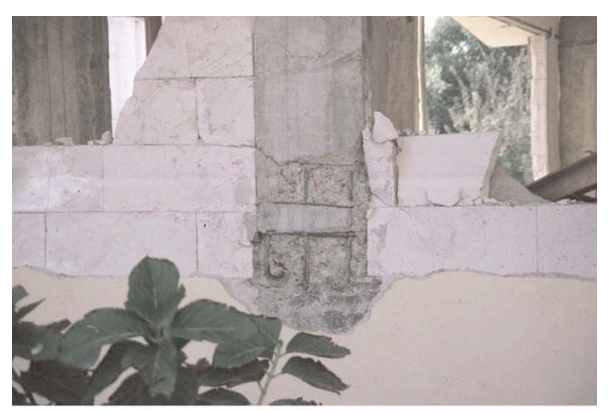

(a)
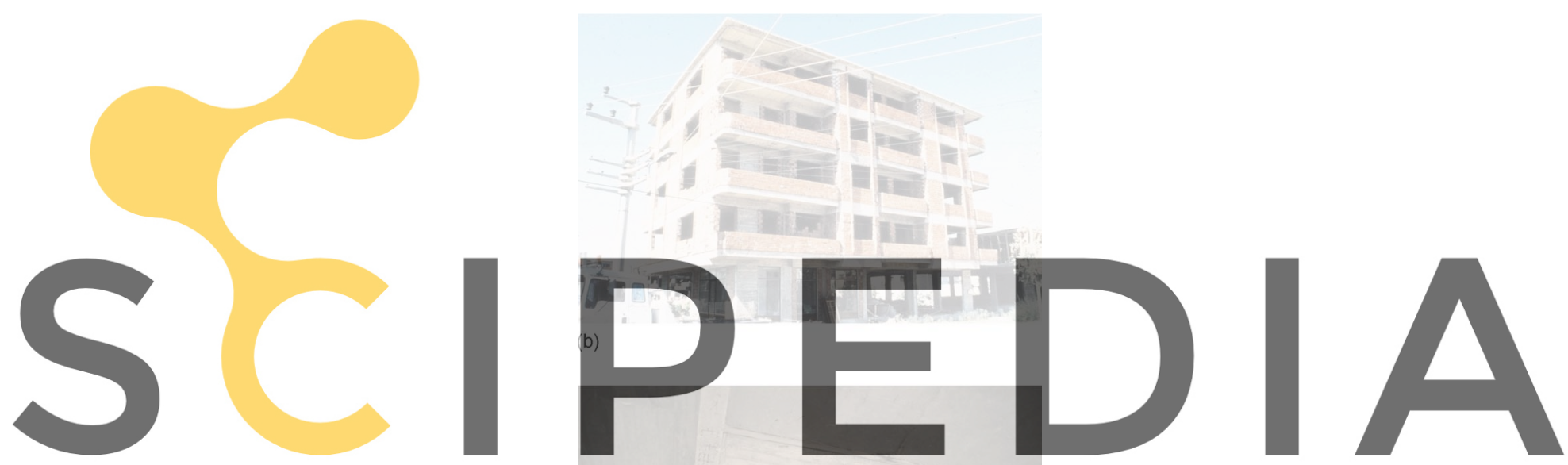

Register for free at https//www.scipedia.com to download the version without the watermark

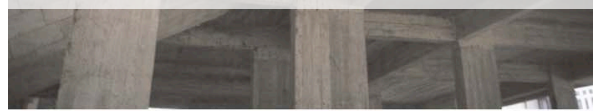

(c)

Figure 5. Pre-existent conditions: (a) Bad construction quality; (b) Vertical shape irregularities, soft floor; (c) Bad structural configuration of the beams and columns.

calibration. Table 3 shows the indices proposed together with those proposed by Park et al. (1984) and Sanchez-Silva and Garcia (2001), which have been included with the aim of comparison. The indices of Park et al. (1984) have been used for reinforced concrete as initial values because they have been calibrated with both experimental data and numerical studies. Some authors consider that collapse occurs for a value equal to 0.8 , although Stone and Taylor (1993) proposed a collapse threshold of 0.77. According to this opinion, a value of 0.76 has been selected in this study to describe the index corresponding to the structural collapse. The authors decided to be conservative when select- 

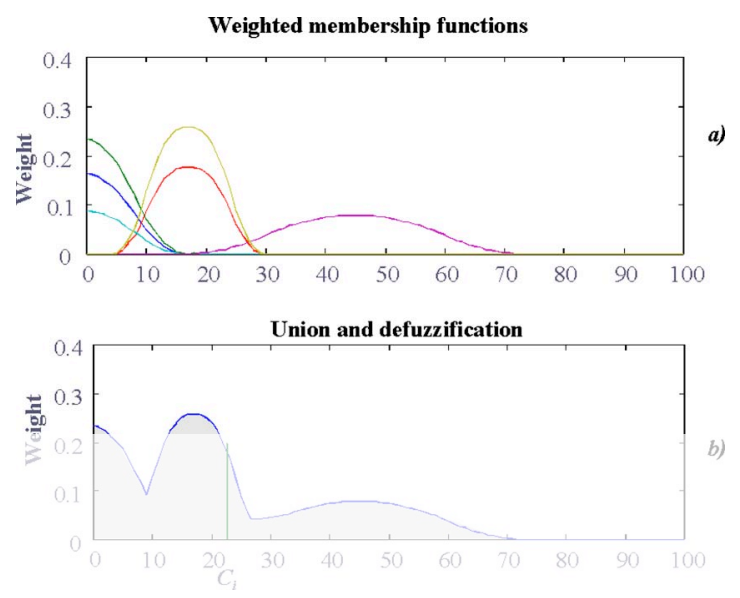

Figure 6. Damage level evaluation for structural elements. (a) Example of fuzzy sets; (b) envelope of the fuzzy sets union. Point $C_{i}$, which corresponds to the centroid of the shaded area limited by the envelope, is the defuzzified value.
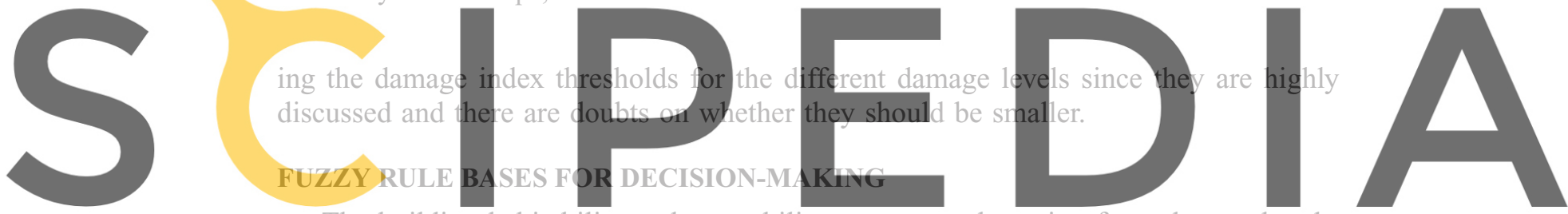

The building habitability and reparability are assessed starting from the results ob-

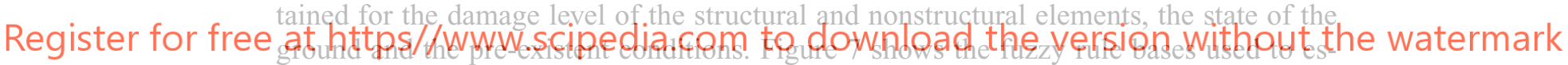
timate the building habitability and reparability. The level of the building damage is evaluated starting from the values of the structural and nonstructural damage index. Then, the global building state is determined, also taking into account the rule bases of

Table 3. Comparative table of damage indices for the same states and ranges (AIS 2003b)

\begin{tabular}{|c|c|c|c|}
\hline Damage Level & Park, Ang and Wen & Sanchez-Silva and Garcia & Proposed \\
\hline Very light & $\begin{array}{c}<0.10 \\
0.07\end{array}$ & 0.10 & 0.07 \\
\hline Light & $\begin{array}{c}0.10-0.25 \\
0.17\end{array}$ & 0.20 & 0.17 \\
\hline Moderate & $\begin{array}{c}0.25-0.40 \\
0.325\end{array}$ & 0.35 & 0.33 \\
\hline Severe & $\begin{array}{c}0.40-0.80 \\
0.6\end{array}$ & 0.60 & 0.55 \\
\hline Collapse & $\begin{array}{c}>0.80 \\
0.8\end{array}$ & 0.90 & 0.76 \\
\hline
\end{tabular}




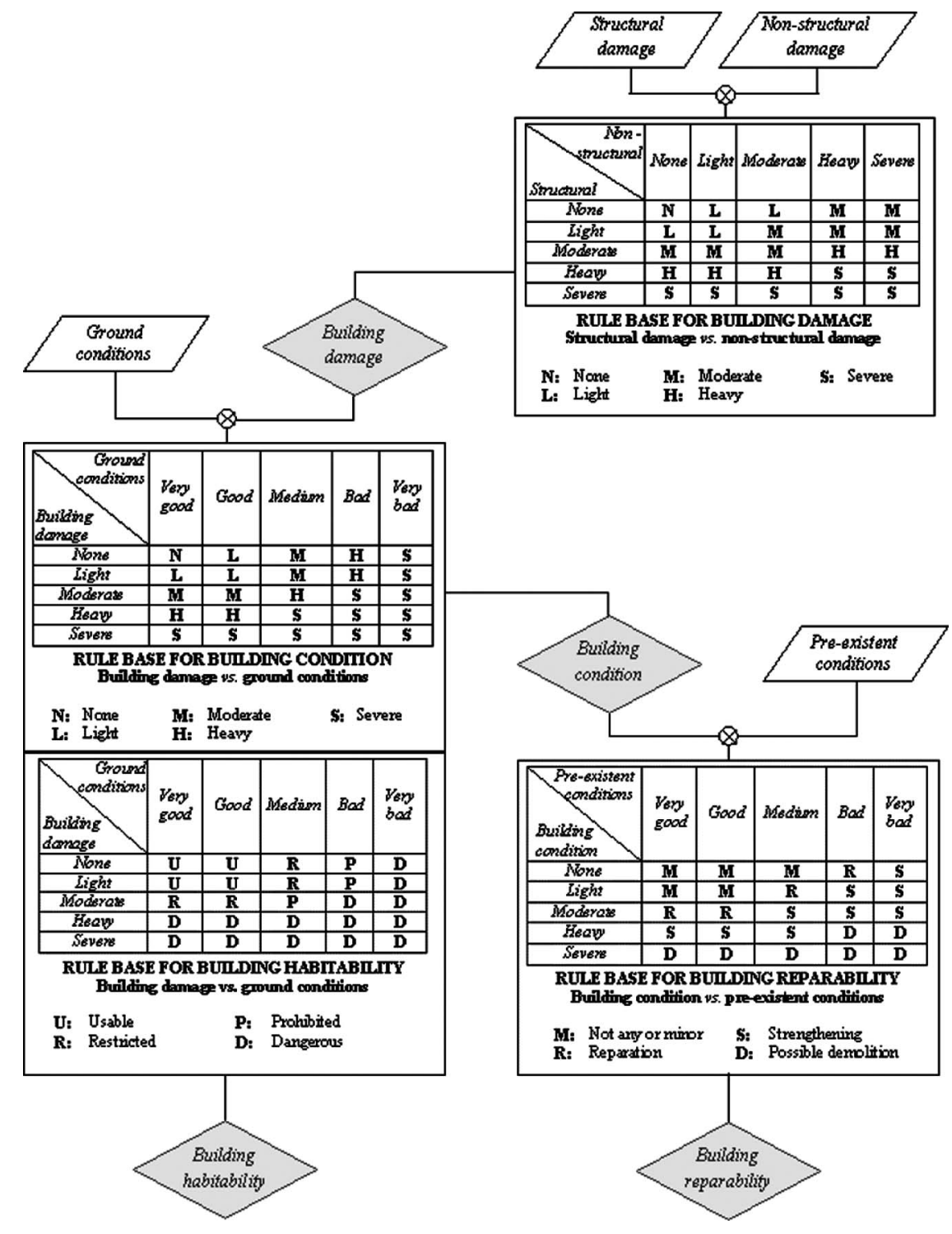

Figure 7. Method for building habitability and reparability evaluation by means of fuzzy rule bases.

the ground conditions, and in this way, the habitability of the building is decided. The linguistic qualification for the building habitability has four possibilities: usable (habitable immediately), restricted use (usable after reparation), dangerous (usable after structural reinforcement), and prohibited (not usable at all). Besides, the building's reparability also depends on other fuzzy rule bases - namely, the pre-existent conditions. The 


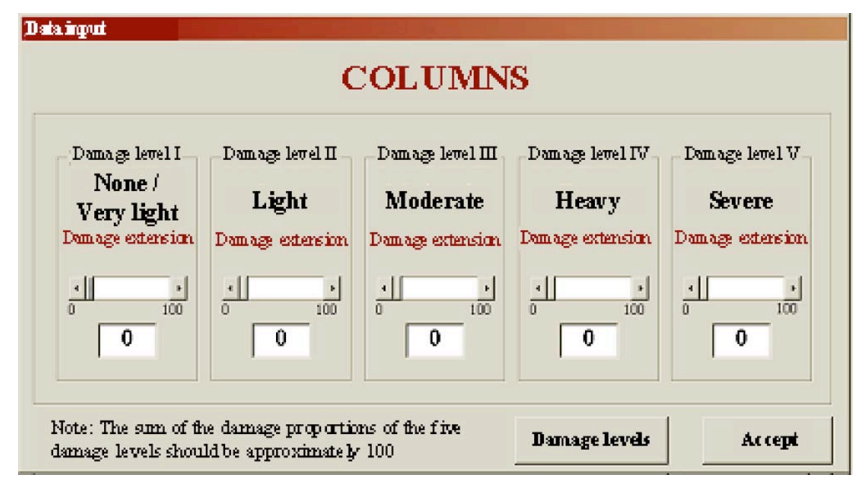

Figure 8. Screen for the damage evaluation of a structural element.

building reparability has four possibilities: not any or minor treatment, reparation, reinforcement, and possible demolition.

\section{COMPUTER PROGRAM EDE}

The proposed computational intelligence model has been implemented in the computer program Earthquake Damage Evaluation of Buildings (EDE), which is used as an official tool by the disaster risk management offices of the cities of Bogotá and Manizales in Colombia. This user-friendly computer program is a very useful tool after a seismic emergency. The program supports the evaluation using as starting point the visual appreciation of the inspectors. Figure 8 shows an example of the data input for the damage in structural elements; the inspector indicates the proportion of elements with a certain damage level. The EDE program provides descriptions and photographs that describe the damage levels for each type of element. Figure 9 shows an example of these helps for structural damage in columns. The model takes into account the pre-existent conditions. The developed computer program can be also used for training of the inspectors before an earthquake.

\section{EXAMPLES OF APPLICATION OF THE COMPUTATIONAL TOOL}

\section{EXAMPLE 1: REINFORCED CONCRETE BUILDING}

The building in Figure 10, built between 1984-1997 in the Coffee-Growing-Region of Colombia, has a structural system based on reinforced-concrete frames and solid slabs floors. It is a six-story corner building on the block without a basement floor. This building was affected by the earthquake of 1999 in the Coffee-Growing-Region. A rapid evaluation shows that the general conditions of the building are not bad, that neither the building nor any of the stories tilted, that no settlements in the foundation are visible, and that the most damaged is the first story. A detailed inspection provided the structural damage data given in Table 4. Figure 11 shows details of the damage suffered by the columns. 


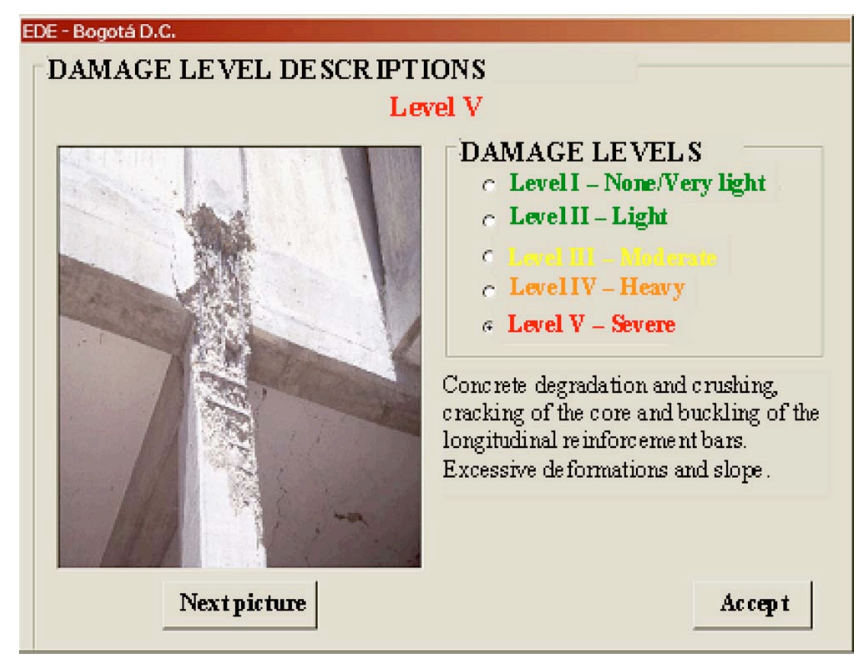

Figure 9. Screen containing the description of severe damage in concrete columns, supporting the evaluation process.

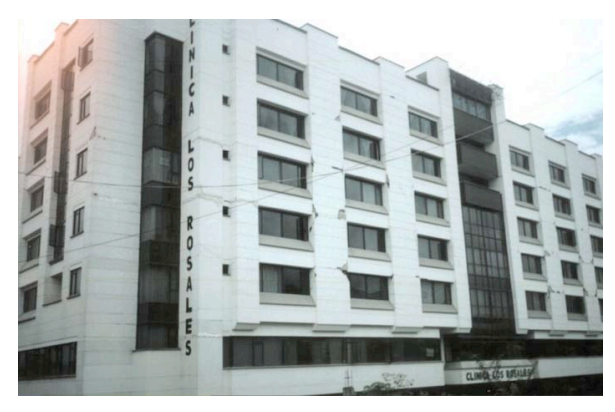

Figure 10. Building of the Coffee-Growing-Region of Colombia damaged by the January 1999 earthquake.

Table 4. Percentages of elements having a given damage level

\begin{tabular}{cllccc}
\hline \hline Element & \multicolumn{5}{c}{ Damage levels (\% of elements) } \\
\hline Beams & None: 30 & Light: 50 & Moderate: 10 & Heavy: 10 & Severe: 0 \\
Columns & None: 35 & Light: 35 & Moderate: 10 & Heavy: 20 & Severe: 0 \\
Joints & None: 60 & Light: 30 & Moderate: 0 & Heavy: 10 & Severe: 0 \\
Floors & None: 40 & Light: 60 & Moderate: 0 & Heavy: 0 & Severe: 0 \\
\hline \hline
\end{tabular}




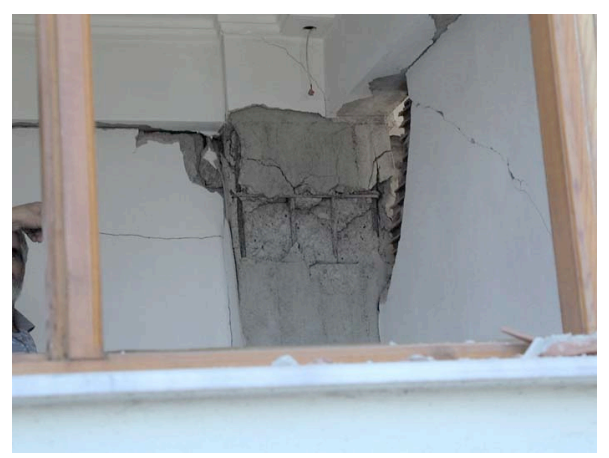

Figure 11. Column with heavy damage.

Referring to nonstructural elements, the damage in the partition walls is moderate, in the façade, light and, in the stairs, heavy. Figure 12 shows an example of damage in a partition wall. The ground conditions are very good, because no cracks, slope instability, landslides, ground settlements, and liquefaction are visible. The pre-existent conditions are good. The quality of the material and of the construction is not good, but the irregularities in plane and elevation are minimal and the structural configuration is good.

\section{Results for Example 1}

All the numerical and linguistic results, comments, and descriptions for the four aspects of the problem - damage, risk, habitability, and reparability - are given by the computer program Earthquake Damage Evaluation of Buildings (EDE):

Damage. The damage results are given using both numerical and linguistic qualifications for each group of elements. The structural damage index is 0.30 what, according to the proposed scale, means that the damage is moderate. The nonstructural damage index is 0.38 , that is, the nonstructural damage is moderate. The ground conditions are very good, the value of the index being 0.05 . The pre-existent conditions are qualified as good, and the value of the corresponding index is 0.25 .

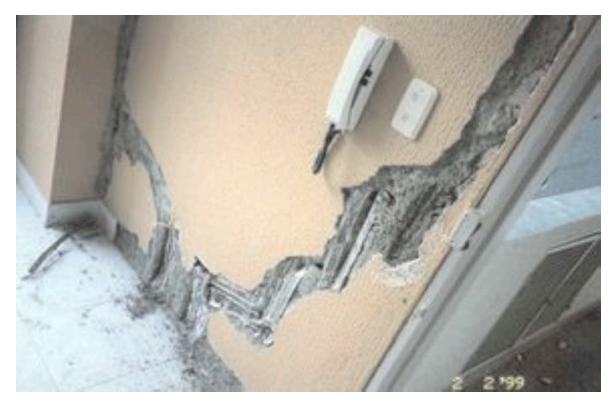

Figure 12. Partitions walls with moderate damage. 


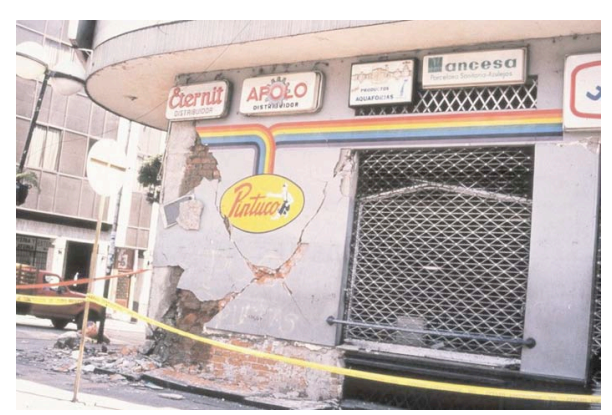

Figure 13. Building of the Coffee-Growing-Region of Colombia damaged by the January 1999 earthquake.

Risk. The safety level is given using linguistic qualification corresponding to the structure, to the nonstructural elements and to the ground and also evaluates the overall state of the building. The structural risk is low after taking some security measures, the nonstructural risk is low after taking some security measures and the ground risk is low. The building damage is moderate and the result provided by the computer code EDE is: "The building has structural and nonstructural moderate damage. The damage can put in danger the building stability in the case of an aftershock. The earthquake resistance has been reduced." Referring to the building condition, EDE states, "The building damage is moderate and the ground conditions are good."

Applying the fuzzy rule bases of Figure 7 to the obtained damage qualifications, the building habitability and reparability are evaluated in the following way:

Habitability. The decision regarding the habitability of the building is given by the EDE code which also suggests security measures which have to be undertaken urgently. The access to the building analyzed in this example should be restricted. The use of the building is assured if the elements in danger to fall are removed or repaired. The inhabitants are at risk.

Reparability. Certain reparation measures that have to be applied are also given by the EDE code, but without a detailed description. Obviously, the development of detailed reparation measures requires the intervention of structural engineers. The building in this example needs some reparation, possibly due to minor damages and pre-existent conditions. It is recommended to undertake a study of its seismic vulnerability.

\section{EXAMPLE 2: UNREINFORCED MASONRY BUILDING}

The building in Figure 13, built between 1950-1984 in the Coffee-Growing-Region of Colombia, has a structural system based on unreinforced masonry and solid slabs floors. It is a three-story building placed on the corner of its block, without a basement floor. This building was affected by the 1999 earthquake in the Coffee-Growing-Region. A rapid evaluation shows that the general conditions of the building are not so bad, that neither the building nor any of the stories tilted, that no settlements in the foundation are 
Table 5. Percentages of elements having a given damage level

\begin{tabular}{cccccc}
\hline \hline Element & \multicolumn{5}{c}{ Damage levels (\% of elements) } \\
\hline $\begin{array}{c}\text { Bearing wall } \\
\text { Floors }\end{array}$ & None: 0 & Light: 30 & Moderate: 20 & Heavy: 50 & Severe: 0 \\
\hline \hline
\end{tabular}

visible and that most of the damaged occurred in the first story. A detailed inspection provided the structural damage data shown in Table 5. Figure 14 shows detail of the damage suffered by the bearing walls.

Referring to the nonstructural elements, the damage in the partition walls is heavy, in the façade is moderate, and in the stairs is light. Figure 15 shows an example of damage in a partition wall. The ground conditions are very good, because no cracks, slope instability, landslides, ground settlements, and liquefaction are visible. Although the building has no irregularities in plane and elevation, and the structural configuration is good, the quality of the material and of the construction is very bad and, for this reason, the pre-existent conditions are very bad.

\section{Results for Example 2}

Damage. The damage results are given using both numerical and linguistic qualifications for each group of elements. The structural damage index is 0.55 , which according to the proposed scale, means that the damage is heavy. The nonstructural damage index is 0.40 , that is, moderate. The ground conditions are very good, the value of the index being 0.05 . The pre-existent conditions are qualified as very bad and the value of the corresponding index is 0.76 .

Risk. The safety level is given using linguistic qualification corresponding to the structure, to the nonstructural elements and to the ground and also evaluates the overall state of the building. The structural risk is high, the nonstructural risk is low after taking some security measures and the ground risk is low. The building damage is heavy and the result provided by the computer code EDE is: "The building has heavy damage in

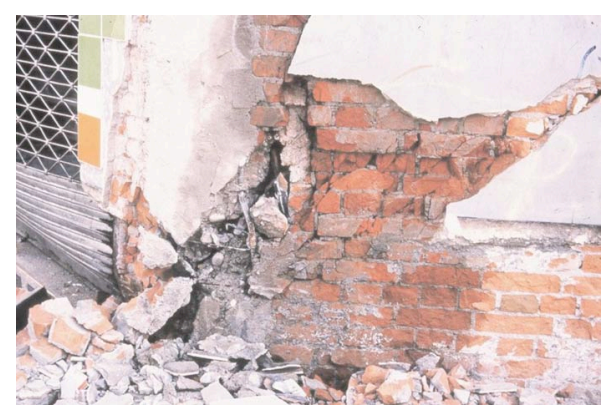

Figure 14. Bearing wall with heavy damage. 


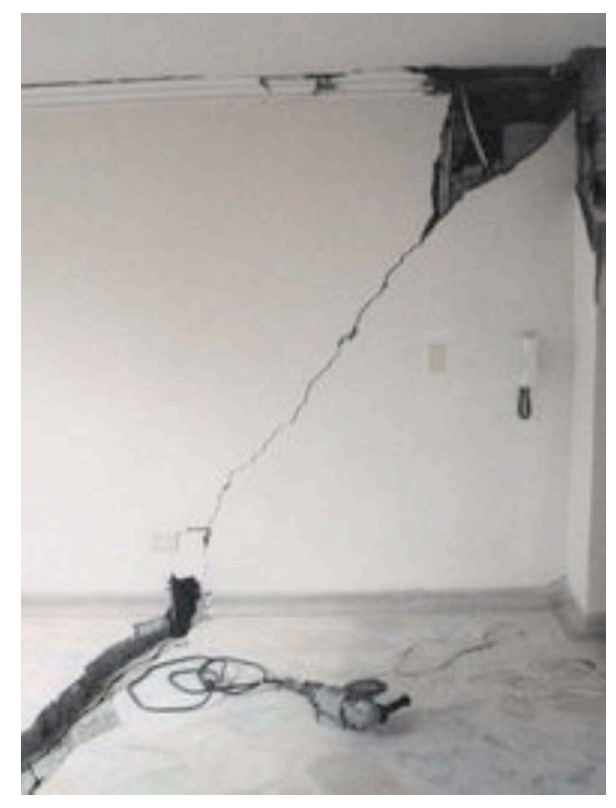

Figure 15. Partitions walls with heavy damage.

the structure and nonstructural moderate damage. The building stability and security have been affected. The earthquake resistance has been reduced." Referring to the building condition EDE states, "The building damage is heavy and the ground conditions are good."

Applying the fuzzy rule bases of Figure 7 to the obtained damage qualifications, the building habitability and reparability are evaluated in the following way:

Habitability. The decision regarding the habitability of the building is given by the EDE code, which also suggests security measures that have to be undertaken urgently. The building is classified as noninhabitable. Access to the building puts the safety of its inhabitants in danger.

Reparability. The building possibly needs to be demolished due to heavy damage and the very poor pre-existent conditions. Obviously, the final decision for demolition requires the intervention of structural engineers.

\section{CONCLUSIONS}

A computer program based on a soft computational model useful in the complex task of building damage evaluation after a strong earthquake has been developed, which improves the existing conventional methodologies and makes possible a more accurate evaluation by nonexpert professionals when there are doubts on the structural safety. The model is based on artificial neural networks and a fuzzy logic approach, and it is suitable in building damage evaluation, which deals with subjective and incomplete information 
and requires the use of linguistic qualifications that are appropriately handled by fuzzy sets. An artificial neural network has been used to calibrate this computational intelligence model using the judgment of specialists. The training of the neural network was performed by using a database of real seismic damage evaluations made by expert engineers. The above-mentioned user-friendly computer program, called Earthquake Damage Evaluation of Buildings (EDE) is used as an official tool for the disaster risk management of the cities of Bogota and Manizales, in Colombia, and is a component of a "National Program on Building Evaluations" of Colombia, in which new inspection guidelines and forms have been also developed.

The calibration of the model depends on the availability of reliable databases of building damage, obtained by experts, which are essential for the learning process of the artificial neural network. These databases are not always available in the desired amount on exception reinforced concrete frames and masonry buildings. Therefore, it is necessary to perform, after future earthquakes, evaluations for all the building classes existing in the seismic areas, reinforced concrete frames and masonry buildings considered in this article, in order to complete the learning process for other constructions, and to improve the calibration. More information on the structural classes for which evaluation databases are already available is also desirable in order to improve the databases.

\section{ACKNOWLEDGMENTS}

This work has been partially sponsored by the Universities and Research Commissionate of the Generalitat de Catalunya (Beatriu de Pinos grants program), Applied Research Grants for Disaster Reduction program of the ProVention Consortium of the World Bank, the Colombian Association for Earthquake Engineering, AIS, the Spanish Ministry of Education and Science (SEDUREC, CONSILDER CSD 2006-00060), and the European Commission (project: Methods for the Improvement of Vulnerability Assessment in Europe, MOVE, FP7-ENV-2007-1-211590).

\section{APPENDIX A. DESCRIPTION OF THE ARTIFICIAL NEURAL NETWORK}

The computational tool uses an artificial neural network (ANN) with an input layer, an intermediate or hidden layer, and an output layer. This appendix describes this neurofuzzy system (Carreño et al. 2006, Carreño 2006).

Input layer of the artificial neural network. The neurons in the input layer are grouped in four sets: structural elements (SE), nonstructural elements (NE), ground conditions (GC), and pre-existent conditions (PC). The input data for this layer are, in the case of the structural elements, the percentages of elements corresponding to each damage level and, in the case of nonstructural elements, the global linguistic qualifications of each element. The fuzzy sets (see Zadeh 1965) for each variable $i$ (for instance, columns, walls, or beams) of the input layer are obtained from the linguistic qualifications obtained after a visual inspection of the building, which provide the damage $D_{j}$ at each level $j$ and its extension or weight $w_{j}$. The damage extension, or percentage of each damage level in each element, varies from 0 to 100 

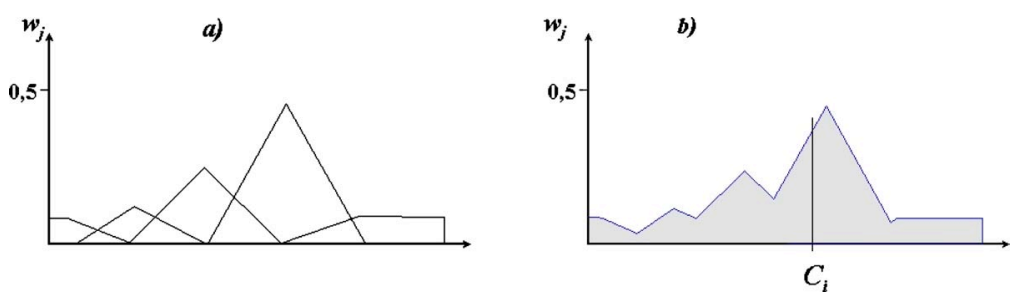

Figure A1. Damage level evaluation for structural elements. (a) Fuzzy sets, (b) Envelope of the fuzzy sets union. The point $C_{i}$ corresponds to the centroid of the area limited by the envelope.

$$
w_{j}=\frac{D_{j}}{\sum_{N} D_{j}}, \quad \sum_{N} w_{j}=1,
$$

The accumulated qualification of damage $D_{i}$ for each variable is the union of the scaled fuzzy sets, taking into account the damage membership functions $\mu_{D_{j}}\left(D_{j}\right)$ and their extensions or weights assigned by the inspector

$$
\begin{gathered}
D_{i}=\left(D_{N} \cup D_{L} \cup D_{M} \cup D_{H} \cup D_{S}\right) \\
\mu_{D_{i}}(D)=\max \left(w_{N, i} \times \mu_{D_{N}}\left(D_{N, i}\right), \ldots, w_{S, i} \times \mu_{D_{S}}\left(D_{S, i}\right)\right)
\end{gathered}
$$

In theory, the union of fuzzy sets is represented by the maximum membership or dependency (see Nauck et al., 1997, Jang et al. 1997). By means of defuzzification, that is, by calculating the centroid of the area of the fuzzy sets union, a qualification index $C_{i}$ is obtained for each variable of each group of neurons (see Figure A1)

$$
C_{i}=\left\lfloor\max \left(w_{N, i} \times \mu_{D_{N}}\left(D_{N, i}\right), \ldots, w_{S, i} \times \mu_{D_{S}}\left(D_{S, i}\right)\right)\right\rfloor_{\text {centroid }}
$$

Each variable predefines the basic membership functions for the fuzzy sets corresponding to the five possible levels of damage. The linguistic qualifications change in each case. Figure A1 shows this process.

Intermediate or hidden layer of the ANN. This layer has four neurons corresponding to each group of variables: structural elements, nonstructural elements, ground conditions and pre-existent conditions. Figure A2 shows a detailed scheme of the evaluation process. In this neural network model, the inputs of the four neurons are the qualifications $C_{i}$ of each variable for each group of neurons and their weights $W_{i}$ which are describing the degree of importance on the corresponding intermediate neuron. These weights have been defined with the participation of experts in earthquake damage evaluation and their values for some structural systems are shown in Table A1. Tables A2-A4 show the initial weights before the training of the ANN for the nonstructural elements, ground conditions and pre-existing conditions. Using these qualifications and weights for each variable $i$, a global index is obtained, for each group $k$, from the defuzzification of the union or maximum membership of the scaled fuzzy sets 


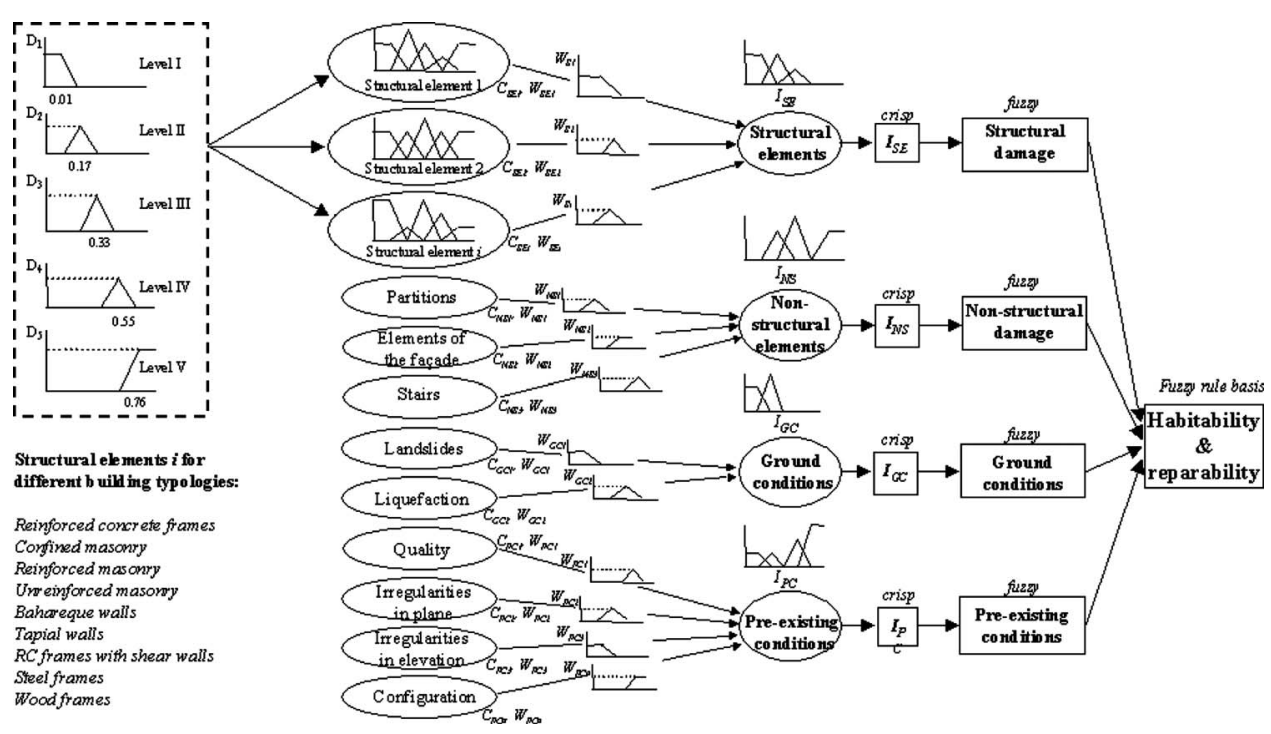

Figure A2. Structure of the proposed artificial neural network.

Table A1. Weights for structural elements according to the building type

\begin{tabular}{ccccccc}
\hline \hline Structural system & Beams & Columns & $\begin{array}{c}\text { Joints or } \\
\text { connections }\end{array}$ & Walls & $\begin{array}{c}\text { Bearing } \\
\text { walls }\end{array}$ & Floors \\
\hline Reinforced concrete frame & 19 & 46 & 25 & - & - & 10 \\
Reinforced concrete structural wall & 15 & - & 20 & 57 & - & 8 \\
Confined masonry & - & - & - & - & 73 & 27 \\
Reinforced masonry & & & & & 73 & 27 \\
Unreinforced masonry & - & - & - & - & 70 & 30 \\
Bahareque walls & - & - & - & - & 77 & 23 \\
Steel frame & 18 & 39 & 35 & - & - & 8 \\
Wood frames & 23 & 45 & 21 & - & - & 11 \\
\hline \hline
\end{tabular}

Table A2. Weights for nonstructural elements

\begin{tabular}{cc}
\hline \hline Element & Weight \\
\hline Partitions & 35 \\
Façade & 35 \\
Stairs & 30 \\
\hline \hline
\end{tabular}


Table A3. Weights for ground conditions variables

\begin{tabular}{c}
\hline $\begin{array}{c}\text { Element } \\
\text { Soil cracks and land slides }\end{array}$ \\
$\frac{\text { Wiquefaction and subsidences }}{50}$ \\
$I_{S E}=\left\lfloor\max \left(W_{S E 1} \times \mu_{C_{S E 1}}\left(C_{S E 1}\right), \ldots, W_{S E i} \times \mu_{C_{S E i}}\left(C_{S E i}\right)\right)\right\rfloor_{\text {centroid }}$ \\
$\mu_{C S E}(C)=\max \left(W_{S E 1} \times \mu_{C_{S E 1}}\left(C_{S E 1}\right), \ldots, W_{S E i} \times \mu_{C_{S E i}}\left(C_{S E i}\right)\right)$,
\end{tabular}

The membership functions $\mu_{C_{k i}}\left(C_{k i}\right)$ and their weights $W_{k i}$ show the notation for the group of structural elements.

Output layer of the ANN. In this layer, a final linguistic qualification is assigned to the global indices obtained for structural elements, nonstructural elements, ground and pre-existent conditions. The damage level is calculated according to the "proximity" of the value to a global damage function of reference, initially defined with the selected damage indices. In this layer, the training process of the neural network is performed. The indices that identify each qualitative level are changed in agreement with the indices calculated in each evaluation and with a learning rate. Once the final qualifications are made, it is possible to determine the global building damage, the habitability and reparability of the building using a set of fuzzy rule bases.

The neural network is calibrated in the output layer where the damage functions are defined in relation to existing damage indices. The initial values are shown in Tables A1-A4. The calibration is made for each damage level and only the indices corresponding to the groups of variables considered in each case are calibrated. The network learning is performed by using a Kohonen network (Kohonen 1982, Kosko 1992)

$$
I_{k j}(t+1)=I_{k j}(t)+\alpha(t)\left\lfloor I_{k j}(t)-I_{k j}\right\rfloor,
$$

where $I_{k j}$ is the value of the damage index of the variables group $k$ recalculated in function of the learning rate a and the difference between the value $I_{k j}(t)$ of the damage index calculated at the present instant and the previous values corresponding to each damage level $j$. The learning rate is given by

Table A4. Weights for pre-existing conditions variables

\begin{tabular}{cc}
\hline \hline Element & Weight \\
\hline Materials quality & 25 \\
Plane shape irregularities & 25 \\
Vertical shape irregularities & 25 \\
Structural configuration & 25 \\
\hline \hline
\end{tabular}




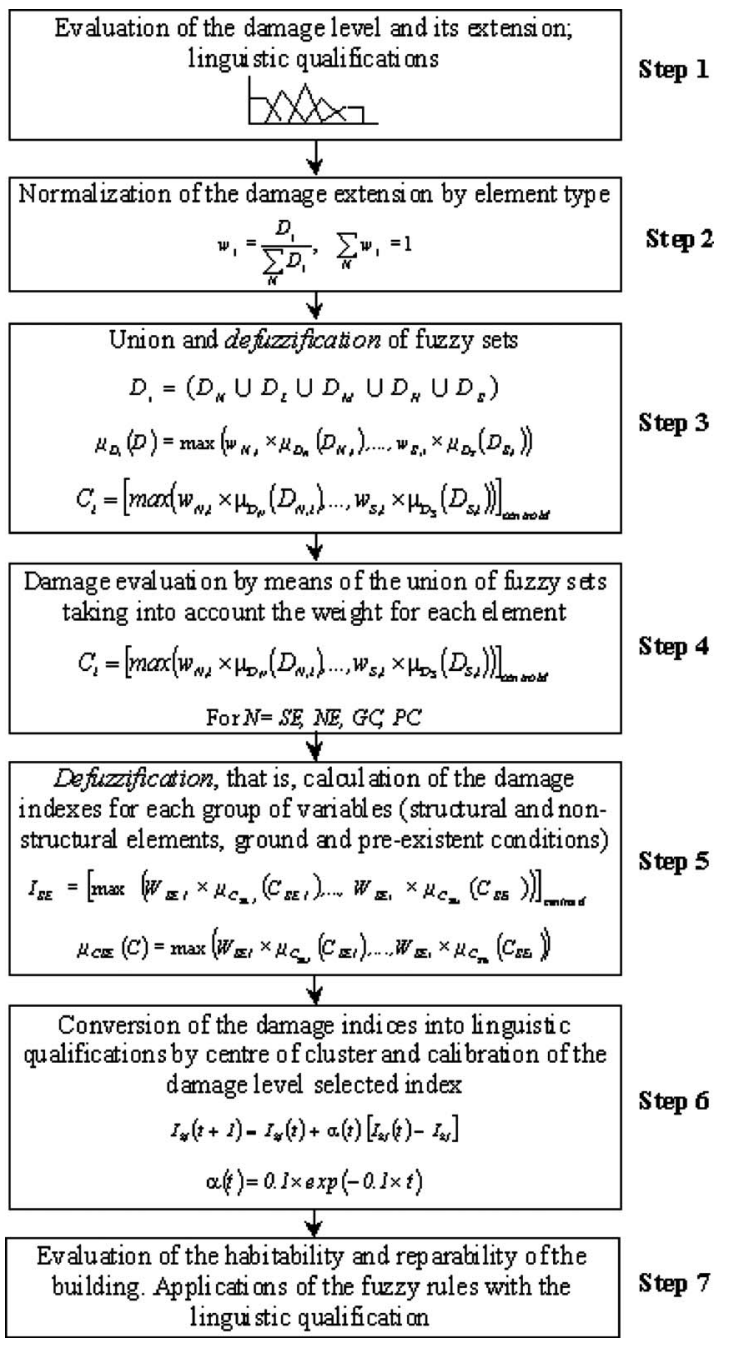

Figure A3. Flow chart for the damage evaluation process.

$$
\alpha(t)=0.1 \times \exp (-0.1 \times t),
$$

where $t$ is the number of times that has been used the index which is calibrated. Figure A3 shows a summary of the computational process which has to be performed according to the proposed model.

\section{REFERENCES}

Applied Technology Council (ATC), 1985. Earthquake Damage Evaluation Data for California, ATC-13, Redwood City, California. 
— 1989. Procedures for Postearthquake Safety Evaluation of Buildings, ATC-20, Redwood City, California.

—, 2003. Users manual: Mobile Postearthquake Building Safety Evaluation Data Acquisition System, (Version 1.0), ATC-20i, Redwood City, California.

—, 2005. Field Manual: Postearthquake Safety Evaluation of Buildings, 2nd edition, ATC20-1, Redwood City, California.

Asociación Colombiana de Ingeniería Sísmica (AIS), 2002. Guía técnica para inspección de edificaciones después de un sismo. Manual de Campo, [Technical guidelines for inspection of buildings after an earthquake: Field Manual], Bogotá, D.C., Colombia.

— 2003a. Manual de Campo para inspección de edificios después de un sismo [Field Manual for inspection of buildings after an earthquake], Bogotá, D.C., Colombia.

— 2003b. Sistema experto para la toma de decisiones de habitabilidad y reparabilidad de edificios después de un sismo. [Expert system for decision-making on habitability and reparability of buildings after an earthquake], Technical report, Alcaldía de Manizales, Oficina Municipal de Prevención y atención de Desastres, Manizales, Colombia.

— 2004. Sistema experto para la evaluación post-sísmica del daño en edificaciones-EDE Bogotá. [Expert system for post-earthquake building damage evaluation], CD-ROM, Bogotá, Colombia.

Barbat, A. H., Oller, S., Oñate, E., and Hanganu, A., 1997. Viscous damage model for Timoshenko beam structures, International Journal of Solids Structures 34, 3953-3976.

Cardona, O. D., 2001. Estimación Holística del Riesgo Sísmico utilizando Sistemas Dinámicos Complejos [Holistic seismic risk estimation using complex dynamic systems], http:// www.desenredando.org/public/varios/2001/ehrisusd/index.html, Technical University of Catalonia, Barcelona, Spain.

Carreño, M. L., 2001. Sistema Experto para la Evaluación del Daño Postsísmico en Edificios [Expert system for post-earthquake building damage evaluation], Master Thesis, Department of Civil and Environmental Engineering, University of Los Andes, Bogotá, Colombia.

— - 2006. Técnicas innovadoras para la evaluación del riesgo sísmico y su gestión en centros urbanos: Acciones ex ante y ex post [Innovative techniques for the evaluation of seismic risk and its management in urban centers: ex ante and ex post actions], doctoral thesis, Technical University of Catalonia, Barcelona, Spain.

Carreño, M. L., Cardona, O. D., and Barbat, A. H., 2006. Neuro-fuzzy assessment of building damage and safety after an earthquake, in Intelligent Computational Paradigms in Earthquake Engineering, Nikos D. Lagaros and Yiannis Tsompanakis, editors, Idea Group, Inc.

—, 2007a. Urban seismic risk evaluation: a holistic approach, Natural Hazards 40, 137-172.

—, 2007b. A disaster risk management performance index, Natural Hazards 41, 1-20.

Demartinos, K., and Dritsos, S., 2006. First-Level pre-earthquake assessment of buildings using fuzzy logic, Earthquake Spectra 22, 865-885.

Federal Emergency Management Agency (FEMA), 1999. Earthquake Loss Estimation Methodology HAZUS, Technical Manual, Vol. I, II and III, first edition 1997, National Institute of Buildings Sciences of Federal Emergency Management Agency, Washington DC.

— 1998. Earthquake Evaluation of Earthquake Damaged Concrete and Masonry Wall Buildings, ATC-43 Project. Prepared for: The Partnership for Response and Recovery, Washington DC.

— 2000. Recommended Seismic Evaluation and Upgrade Criteria for Existing Welded Steel 
Moment-Frame Buildings, Prepared for SAC Joint Venture Partnership by Guidelines Development Committee, Washington DC.

Goretti, A., 2001. Post-Earthquake Building Usability: An Assessment. Technical Report SSN/ $R T / 01 / 03$, Italy.

Institute of Earthquake Engineering and Engineering Seismology (IZIIS), 1984. Methodology and procedure for the evaluation of seismic damage, University Kiril and Metodij, Skopje, Yugoslavia.

Jang, J.-S. R., Sun, C. T., and Mizutani, E., 1997. Neuro-Fuzzy and Soft Computing. A Computational Approach to Learning and Machine Intelligence, Prentice-Hall London, UK.

Kohonen, T., 1982. Analysis of a simple self-organizing process, Biological Cybernetics 43, $59-69$.

Kosko, B., 1992. Neural Networks and Fuzzy Systems: A Dynamical Systems Approach to Machine Intelligence, Prentice-Hall, Englewood Cliffs, NJ.

Nauck, D., Klawonn, F., and Kruse, R., 1997. Foundations of Neuro-Fuzzy Systems, John Wiley and Sons, Chichester, England.

Oller, S., and Barbat, A. H., 2006. Moment curvature damage for bridges subjected to seismic loads, Comput. Methods Appl. Mech. Eng. 195, 4490-4511.

Park, Y. J., Ang, A., and Wen, Y., 1984. Seismic damage analysis and damage-limiting design of R. C. buildings, Structural Research Series, Report No 516, University of Illinois at Urban-Champaign, Urbana.

Rodríguez, M., and Castrillón, E., 1995. Manual de evaluación postsísmica de la seguridad estructural de edificaciones. [Manual for post-earthquake evaluation of structural safety of buildings], Series del Instituto de Ingeniería 569, UNAM, México.

Rutkowska, D., 2002. Neuro-Fuzzy Architectures and Hybrid Learning, Physica Verlag, Heidelberg, Germany.

Sanchez-Silva, M., and García, L., 2001. Earthquake damage assessment based on fuzzy logic and neural networks, Earthquake Spectra 17, 89-112.

Singhal, A., and Kiremidjian, A., 2006. A method for earthquake motion-damage relationships with application to reinforced concrete frames. Technical Report NCEER-97-0008, Buffalo.

Sociedad Mexicana de Ingeniería Sísmica (SMIS), 1998. Manual de evaluación postsísmica de la seguridad estructural de edificaciones [Manual of post-earthquake evaluation of the structural safety of buildings], Secretaria de Obras y Servicios Gobierno del Distrito Federal, Sociedad Mexicana de Ingeniería Sísmica, México.

Stone, W. C., and Taylor, A. W., 1993. Seismic performance of circular bridge columns designed in accordance with ASHTO/CALTRANS standards, NIST Building Science Series 170, National Institute of Standards and Technology, Gaithersburg MD.

Zadeh, L. A., 1965. Fuzzy sets, Information and Control 8, 338-353.

— 1975. The concept of a linguistic variable and its application to approximate reasoning, Information science, Part I, Vol. 8, 199-249 Part II, Vol. 8, 301-357, Part III, Vol. 9, 43-80.

1996. Fuzzy logic and the calculi of fuzzy rules and fuzzy graphs: a précis, Multiple Valued Logic 1, 1-38.

Zuccaro, G., and Papa, F., 2002. Multimedia handbook for seismic damage evaluation and post event macroseismic assessment, Proceedings, XXIII General Assembly of the European Seismological Commission, Genova (CD-ROM).

(Received 22 May 2007; accepted 20 August 2009) 